\title{
Variability among Accessions of Cowpea (Vigna Unguiculata L. Walp): From Qualitative Scoring to Quantitative Analyses
}

\author{
Ajayi Abiola Toyin* \\ *Corresponding Author \\ Ajayi Abiola Toyin

\section{Article History} \\ Received: 07.08.2019 \\ Accepted: 15.08 .2019 \\ Published: 20.08.2019
}

Department of Plant Science and Biotechnology, Adekunle Ajasin University, Akungba-Akoko, Nigeria

\begin{abstract}
Genetic variability and inter-character association in 25 accessions of cowpea were studied through their expression of qualitative morphological traits. Accessions were collected from the Genetic Resources Centre of the International Institute of Tropical Agriculture (IITA), Ibadan and assessed in the field in a Randomized Complete Block Design (RCBD) with three (3) replications. Twelve (12) qualitative traits were evaluated utilizing 10 plants for each accession per replication. Heritability and Genotypic correlations were estimated with Plant Breeding Tools (PB-Tools) version 1.4. The information were exposed to cluster and Principal Component (PC) analyses utilizing Palaeontological Statistics Software Package for Education and Data Analysis (PAST). All the 12 qualitative traits separated accessions successfully. Heritability for all traits was 100 percent, which showed that in cowpea, the effect of environment on manifestation of qualitative traits is insignificant. The most variable trait was immature pigmentation (84.24\%) and the trait with the least variability was leaf colour (20.92\%). In the bi-plots, accessions in group I and II which differed to accessions in group IV in important traits such as growth pattern, plant hairiness, pod attachment to peduncle and leaf colour are recommended together with these important traits in cowpea improvement programmes. Conclusively, combination of PCA, bi-plot, cluster analysis and genotypic correlations were efficient in revealing significant relationships among characteristics of cowpea accessions for selection purposes, and are therefore recommended.
\end{abstract}

Keywords: Cluster analysis, PCA, qualitative traits, bi-plots, environment

\section{INTRODUCTION}

Cowpea is one of the most important grain legumes in the tropical and sub-tropical regions of the world. It serves as a source of protein in the diets of the people for its protein content of between $20-29 \%$; and also has a remarkable capacity to fix atmospheric nitrogen in soil [1, 2] for maintenance of soil nutrients. Compared to cultivation of cereals in terms of crop area, cowpea occupies a smaller proportion, yet contributes significantly to domestic food security in many African countries [3]. Its choice among the people of the drier regions of the world lies in its ability to tolerate drought, high temperatures and other abiotic stresses compared with other crop species [4-6].

In spite of these great attributes of cowpea, coupled with the fact that many improved varieties expressing combination of different traits, have been developed and released in many countries [7], productivity of the crop has been limited by factors such as inadequate grain yields, poor grain feature and proneness to diseases and pests, and nonexistence of enhanced cultivars [1]. Inadequate knowledge of the level of genetic diversity of the existing germplasm has been responsible for the limited genetic enhancement of cowpea. Selection of suitable genotypes for different environmental constraints is restricted by inadequate screening techniques and absence of genotypes expressing clear phenotypic differences for environmental constraints [2]. Furthermore, cowpea requirements on varietal basis in terms of combination of traits are region specific, hence making breeding programme for improvement of the crop more difficult $[8,1]$.

The full knowledge of the level of genetic variability in a crop species for many traits is important prior to commencement of any crop improvement programme. Information on the nature and degree of unevenness in the obtainable material of plant and correlation among the various traits is indispensable for crop improvement. Consequently, records on germplasm collection and diversity are highly desirable for successful plant breeding programme [1]. The over 15, 000 cowpea accessions preserved at the

Copyright @ 2019: This is an open-access article distributed under the terms of the Creative Commons Attribution license which permits unrestricted use, distribution, and reproduction in any medium for non commercial use (NonCommercial, or CC-BY-NC) provided the original author and source are credited. 
International Institute of Tropical Agriculture (IITA) Gene Bank, head quarter in Nigeria have been the precursor for newly improved varieties [1]; still, little information on genetic diversity from Gene Bank records is available to the breeders in Nigeria, hence making selection and improvement of the crop more difficult.

Worldwide, morphological traits have been exploited lengthily for studying variability and association of attributes in many species of crop [2, 9] in establishing phylogenetic connections among and within species, but evidence available on diversity of cowpea utilizing this approach in Nigeria is not enough. On the other hand, morphological features may be prone to environmental influence, giving rise to fluctuating relationship patterns [10], nevertheless, they are reliable for selection [1]. Scoring of qualitative traits in cowpea has been established to be a genuine alternative to molecular and biochemical techniques in studying genetic variability of its germplasm collections and providing important information on genetic relationship of the crop desired for breeding programmes [11]. The aim of this research was to determine the level of genetic diversity and inter trait association of accessions of cowpea of different origins using qualitative morphological scoring methodology with the hope of utilizing outcomes of the study to support breeding programmes of the crop.

\section{Materials and Methods}

This research to study the genetic variation in 25 accessions of cowpea (Table 1) collected from the International Institute of Tropical Agriculture (IITA), Ibadan was done between May and October, 2015 at the Department of Plant Science and Biotechnology Experimental Field; Adekunle Ajasin University, Akungba-Akoko, Nigeria. The site of the experiment was located on Latitude $7.2^{\circ} \mathrm{N}$, Longitude 5.44' $\mathrm{E}$ and Altitude $423 \mathrm{~m}$ above sea level. These accessions were assessed in the field utilizing a Randomised Complete Block Design (RCBD) and replicated three times. Dimension of each plot of accession per replicate was $5 \mathrm{~m}$ by $1 \mathrm{~m}$ with inter-plot spacing of $1 \mathrm{~m}$. Twenty (20) plants were sown per accession in each replicate at a spacing of $30 \mathrm{~cm}$ and $50 \mathrm{~cm}$ intra-row and inter-row respectively making the total number of 1500 plants in the field. Data on qualitative traits (Table 2) were collected from 10 randomly tagged plants per accession in each replicate in accordance with descriptors of cowpea, International Board of Plant Genetic Resources [12]. Plant Breeding Tools (PB-Tools) version 1.4 (Biometrics and Breeding Informatics, International Rice Research Institute) was utilized for Heritability and Genotypic correlation estimations. Cluster analysis, Principal Component analysis and Biplots were done adopting Palaeontological Statistics Software Package for Education and Data Analysis (PAST), Hammer et al. [13].

Table -1: Names and origin of the 25 accessions of cowpea used for genetic variability

\begin{tabular}{|l|l|l|l|}
\hline S/N & Accession & Country of origin & Code \\
\hline 1 & TVu-7362 & Ghana & AC01 \\
\hline 2 & TVu-185 & Nigeria & AC02 \\
\hline 3 & TVu-199 & USA & AC03 \\
\hline 4 & Tvu-207 & USA & AC04 \\
\hline 5 & Tvu-218 & USA & AC05 \\
\hline 6 & Tvu-224 & USA & AC06 \\
\hline 7 & Tvu-235 & Ghana & AC07 \\
\hline 8 & Tvu-236 & Ghana & AC08 \\
\hline 9 & Tvu-239 & South Africa & AC09 \\
\hline 10 & Tvu-241 & USA & AC10 \\
\hline 11 & IT98K-205-8 & Nigeria & AC11 \\
\hline 12 & IT98K-555-1 & Nigeria & AC12 \\
\hline 13 & Tvu-4886 & Niger & AC13 \\
\hline 14 & Tvu-4866 & Niger & AC14 \\
\hline 15 & Tvu-8660 & Benin & AC15 \\
\hline 16 & Tvu-9225 & Tanzania & AC16 \\
\hline 17 & Tvu-11986 & Sudan & AC17 \\
\hline 18 & Tvu-9256 & Burkina Faso & AC18 \\
\hline 19 & Tvu-9252 & Burkina Faso & AC19 \\
\hline 20 & Tvu-11979 & Sudan & AC20 \\
\hline 21 & IT97K-568-18 & Nigeria & AC21 \\
\hline 22 & IT89K-288 & Nigeria & AC22 \\
\hline 23 & IT96-610 & Nigeria & AC23 \\
\hline 24 & IT81-994 & Nigeria & AC25 \\
\hline 25 & IT89K-391 & Nigeria & \\
\hline
\end{tabular}


Table-2: List of 12 qualitative traits examined in 25 accessions of cowpea

\begin{tabular}{|l|l|l|l|}
\hline S/N & Trait & Period & Scoring scale \\
\hline 1 & Growth pattern & Maturity & $1=$ determinate; $2=$ indeterminate \\
\hline 2 & Twinning tendency & 5 WAP & $0=$ none; $3=$ slight; $5=$ intermediate; $7=$ pronounced \\
\hline 3 & Plant pigmentation & 5 WAP & $0=$ none; $1=$ very slight; $3=$ moderate; $5=$ intermediate; $7=$ extensive; $9=$ solid \\
\hline 4 & Terminal leaflet shape & 5 WAP & $1=$ globose; $2=$ sub-globose; $3=$ sub-hastate; $4=$ hastate \\
\hline 5 & Plant hairiness & 5 WAP & $3=$ glabrescent; $5=$ short hairs; $7=$ pubescent to hirsute \\
\hline 6 & Raceme position & Maturity & $1=$ mostly above canopy; $2=$ in upper canopy; $3=$ throughout canopy \\
\hline 7 & Pod attachment to peduncle & Maturity & $3=$ pendant; $5=30$ - $90^{0}$ down to erect; $7=$ erect \\
\hline 8 & Pod curvature & Maturity & $0=$ straight; $3=$ slightly curved; $5=$ curved; $7=$ coiled \\
\hline 9 & Immature Pod pigmentation & Maturity & $\begin{array}{l}0=\text { none; } 1=\text { pigmented tip; } 2=\text { pigmented sutures; } 3=\text { pigmented valves; } 4=\text { splashes of } \\
\text { pigment; } 5=\text { uniformly pigmented }\end{array}$ \\
\hline 10 & Leaf colour & 5 WAP & $3=$ pale green; $5=$ intermediate green; $7=$ dark green \\
\hline 11 & Flower colour & Maturity & $1=$ white; $2=$ violet; $3=$ pink; $4=$ other \\
\hline 12 & Pod colour (matured) & Maturity & $0=$ none1 = pale tan; $2=$ dark tan; $3=$ dark brown; $4=$ black or dark purple; $5=$ other \\
\hline
\end{tabular}

WAP = Weeks after planting

\section{RESULTS}

\section{Variability among 25 accessions of cowpea based on qualitative traits}

The variation among the 25 accessions established on mean scores of qualitative attribute is presented in Table 3 . The most variable traits included immature pod pigmentation $(C V=84.24 \%)$, plant pigmentation $(C V=76.25 \%)$ and pod curvature $(71.56 \%)$, terminal leaflet shape (CV $=46.35 \%)$, Pod colour ( $C V=45.09 \%$ ) and raceme position $(C V=45.09 \%)$. The least variable trait was leaf colour (CV $=20.92 \%)$. Heritability was $100 \%$ for all the qualitative traits.

\section{Growth pattern (GTP)}

Two (2) groups were obtained based on similar mean values: Group 1 had twelve accessions (AC01, AC02, AC03, AC05, $A C 12, A C 13, A C 14, A C 15, A C 18, A C 19, A C 23$ and $A C 24)$ each with mean value of 1. These accessions had determinate growth pattern. Group 2 consisted of thirteen accessions (AC04, AC06, AC07, AC08, AC09, AC10, AC11, AC16, AC17, AC20, AC21, AC22 and AC25) with mean value of 2 each. These accessions had indeterminate growth pattern.

\section{Twinning tendency (TWT)}

Four (4) groups were obtained: Group 1 consisted of two accessions (AC04 and AC11) with value of 0 each. These accessions had no twinning tendency. Group 2 consisted of six accessions (AC02, AC05, AC08, AC12, AC18 and AC23) each with mean of 3 . These accessions were twinned slightly. Group 3 consisted of eight accessions (AC01, AC03, AC06, AC09, AC13, AC14, $A C 21$ and $A C 24)$ each with mean of 5. These accessions had intermediate twinning. Group 4 consisted of eight accessions (AC10, AC15, AC16, AC17, AC19, AC20, AC22 and AC25) each with mean of 7; with pronounced twinning.

\section{Plant pigmentation (PP)}

Six (6) groups were obtained for this trait: Group 1 consisted of three accessions (AC09, AC22 and AC25) each with mean value of 0 . These accessions had no pigments. Group 2 had six accessions (AC01, AC04, AC11, AC16, AC19 and AC21) each with mean value of 1 . These accessions were slightly pigmented. Group 3 consisted of four accessions (AC03, AC08, AC17 and AC20) each with mean of 3 . These accessions were moderately pigmented at the tips and bases of petioles. Group 4 consisted of four accessions (AC02, AC05, AC06 and AC10) each with mean of 5 . These accessions were intermediately pigmented. Group 5 consisted of five accessions (AC07, AC12, AC13, AC14 and AC23) each with mean of 7 and extensively pigmented. Group 6 consisted of three accessions (AC15, AC18 and AC24) with mean value of 9 each. These accessions were solidly pigmented.

\section{Terminal leaflet shape (TLS)}

Four (4) groups were obtained for terminal leaflet shape: Group 1 consisted of nine accessions (AC01, AC07, AC08, AC09, $A C 10, A 17, A C 20, A C 21$ and $A C 25)$ each with mean of 1, with globose leaflet shape. Group 2 consisted of eleven accessions (AC02, $A C 05, A C 12, A C 13, A C 14, A C 15, A C 16, A C 18, A C 19, A C 23$ and AC24) each with mean of 2, with leaflet shape sub-globose. Group 3 had three accessions (ACO3, ACO4 and ACO6) each with mean of 3, with leaflet shape sub-hastate. Group 4 consisted of two accessions (AC11 and AC22) each with mean of 4 . These accessions had hastate leaflet shape.

\section{Plant hairiness (PHR)}

Three (3) groups were obtained for plant hairiness: Group 1 had thirteen accessions (AC01, AC03, AC04, AC07, AC12, $A C 13, A C 14, A C 15, A C 16, A C 18, A C 19, A C 22, A C 23$ and AC24) each with mean of 3 . These accessions had glabrescent hairs. Group 2 consisted of six accessions (AC02, AC05, AC06, AC08, AC10 and AC21) each with mean of 5, with short hairs. Group 3 consisted of five accessions (AC09, AC11, AC17, AC20 and AC25) each with mean of 7, with pubescent hairs. 


\section{Raceme positions (RP)}

Three (3) groups were obtained: Group 1 comprised ten accessions (AC08, AC11, AC16, AC17, AC18, AC19, AC21, AC22, $A C 24$ and $A C 25)$ each with mean of 1; with racemes above canopy mostly. Group 2 had four accessions (AC04, AC05, AC07 and AC09) each with mean of 2. These accessions had their racemes mostly in upper canopy. Group 3 had eleven accessions (AC01, AC02, AC03, AC06, AC10, AC12, AC13, AC14, AC15, AC20 and AC23) each with mean of 3. These accessions had their racemes throughout canopy.

\section{Pod attachment to peduncle (PAP)}

Four (4) groups were obtained: Group 1 had two accessions (AC19 and AC22) each with mean value of 1; with absence of pods. Group 2 consisted of five accessions (AC02, AC05, AC15, AC18 and AC24) each with mean of 3, with pendant attachment of pods to peduncle. Group 3 comprised fourteen accessions (AC03, AC04, AC06, AC07, AC08, AC09, AC10, AC12, AC13, AC14, $A C 16, A C 17, A C 20$ and $A C 25)$ each with mean value of 5, with pod attachment to peduncle in 30 to $90^{\circ}$ down from erect. Group 4 had five accessions (AC01, AC11, AC21 and AC23) each with mean of 7, with erect pod attachment to peduncle.

\section{Pod curvature (PC)}

Five (5) groups were obtained for this trait: Group 1 consisted of six accessions (AC01, AC02, AC05, AC11, AC20 and AC22) each with mean of 0 , accessions with straight pods. Group 2 consisted of one accession (AC19) with mean of 1, an accession without pods. Group 3 consisted of eight accessions (AC04, AC06, AC07, AC08, AC09, AC13, AC14 and AC21) each with mean value of 3 . These accessions had slightly curved pods. Group 4 consisted of eight accessions (AC03, AC10, AC12, AC16, AC17, $A C 18, A C 23$ and AC25) each with mean of 5, accessions with curved pods. Group 5 had two accessions (AC15 and AC24) each with mean of 7 , accessions with coiled pods.

\section{Immature pod pigmentation (IPP)}

Five (5) groups were obtained: Group 1 had five accessions (AC09, AC16, AC19, AC21, AC22 and AC25) each with mean of 0 , accessions without pigments on their pods. Group 2 had six accessions (AC01, AC02, AC07, AC10, AC13 and AC23) each with mean of 1 . These were accessions with pods which had pigmented tips. Group 3 consisted of six accessions (AC08, AC11, AC14, $A C 17, A C 20$ and AC24) each with mean of 2, accessions with pods which had pigmented sutures. Group 4 had one accession (AC03) with mean of 3; an accession with immature pods which were green at the sutures with pigmented valves. Group 5 consisted of five accessions (AC04, AC05, AC06, AC12 and AC18) each with mean of 4, accessions with immature pods with splashes of pigment. Group 6 consisted of one accession (AC15) with mean value of 5 . This accession had uniformly pigmented immature pods.

\section{Leaf colour (LC)}

Three (3) groups were obtained: Group 1 consisted of two accessions (AC02 and AC05) each with mean of 3. These accessions had pale green leaves. Group 2 consisted of seven accessions (AC06, AC07, AC09, AC12, AC14, AC18 and AC19) each with mean of 5 , with intermediate green leaf colour. Group 3 consisted of sixteen accessions (AC01, AC03, AC04, AC08, AC10, $A C 11, A C 13, A C 15, A C 16, A C 17, A C 20, A C 21, A C 22, A C 23, A C 24$ and $A C 25)$ each with mean of 7 , accessions with deep green leaf colour.

\section{Flower colour (FC)}

Four (4) groups were obtained: Group 1 had five accessions (AC01, AC03, AC11, AC19 and AC21) each with mean value of 1, with white flower colour. Group 2 consisted of eleven accessions (AC04, AC05, AC06, AC07, AC09, AC10, AC13, AC14, AC16, $A C 24$ and $A C 25)$ each with mean of 2, accessions with violet flowers. Group 3 had six accessions (AC12, AC15, AC17, AC18, AC20 and AC23) each with mean of 3 . These accessions had mauve-pink flowers. Group 4 consisted of three accessions (AC02, AC08 and AC22) each with mean of 4 , with other flower colours.

\section{Pod colour (PODC)}

Five (5) groups were obtained: Two accessions were contained in group 1 (AC19 and AC22), each with mean of 0 . These accessions had no pods. Group 2 had three accessions (AC06, AC12 and AC13) each with mean of 1; accessions had pods with pale tan or straw colour. Group 3 had twelve accessions (AC02, AC03, AC05, AC07, AC08, AC09, AC10, AC14, AC16, AC17, AC18, AC20 and AC23) each with mean of 2 . These accessions had pods with dark tan. Group 4 consisted of six accessions (AC01, AC04, AC11, $A C 21, A C 24$ and AC25) with mean value of 3 each. These accessions had pods with dark brown colour. Group 5 had one accession (AC15) with mean of 4; an accession with pods which had black or dark purple colour.

\section{Genotypic correlation analysis}

The genotypic correlation among 12 qualitative traits of 25 accessions of cowpea is presented in Table 4. Growth pattern was highly significant and positively correlated with plant hairiness (0.57). It was also positively correlated with pod attachment to peduncle (0.43). Growth pattern was highly significant but negatively correlated with plant pigmentation $(-0.58)$. Plant pigmentation was highly significant and positively correlated with immature pod pigmentation (0.53); positively correlated with pod curvature (0.49). It was also negatively correlated with plant hairiness $(-0.43)$. Pod attachment to peduncle was highly significant and positively correlated with leaf colour (0.52). 


\section{Cluster analysis based on qualitative traits of accessions of cowpea}

Dendrogram of the 25 accessions of cowpea established on the 12 qualitative attributes is shown in Figure 1 . The 25 accessions were divided into four major clusters (I, II, III and IV). Cluster I had two accessions (AC11 and AC04). Cluster II consisted of three sub-clusters (A, B and C). Sub-cluster A had two accessions (AC01 and AC20). Sub-cluster B had four accessions (AC16, $A C 21, A C 25$ and $A C 09$ ). Sub- cluster $C$ had five accessions (AC08, AC17, AC10, AC06 and AC03). Cluster III had only two accessions (AC22 and AC19). Cluster IV had three sub-clusters (A, B and C). Sub-cluster A had two accessions (AC05 and AC02), sub cluster $B$ had two accessions (AC15 and AC24) while sub-cluster $C$ had six accessions (AC18, AC12, AC23, AC14, AC13 and AC07). In cluster I, traits such as growth pattern, twinning tendency and plant pigmentation were responsible for the similarities of its accessions. Accessions in cluster IIA were similar for traits like raceme position, plant pigmentation, leaf colour, and terminal leaflet shape and pod curvature, while accessions in cluster IIB were more similar for traits such as growth pattern and immature pod pigmentation.

Accessions in cluster IIC were similar for pod attachment to peduncle. Accessions in cluster III were similar for traits such as plant hairiness, raceme position, twinning tendency and immature pod pigmentation and pod colour. Accessions in cluster IVA were similar for traits such as growth pattern, twinning tendency, plant pigmentation, and terminal leaflet shape, and plant hairiness, pod attachment to peduncle, leaf colour, pod colour and pod curvature. Accessions in IVB were similar for such as plant pigmentation, growth pattern, terminal leaflet shape, plant hairiness, pod attachment to peduncle, pod curvature and leaf colour. Accessions in cluster IVC were similar for plant hairiness. Cluster II had three accessions originated from USA, while two originated from Nigeria. Also, three accessions in cluster IV originated from Nigeria, while two were from Niger.

\section{Principal Component analysis established on qualitative traits of 25 accessions of cowpea}

The Principal Components, Eigen values and percentage variability of the 25 accessions of cowpea based on qualitative traits are presented in Table 5. Fourteen (14) Principal Component axes were extracted for qualitative traits out of which the first six with Eigen values above 1.00 accounted for $84.19 \%$ of the entire variation. The first Principal Component axis explained $26.02 \%$ of the whole variation. Traits such as growth pattern (0.45), plant hairiness (0.34), and pod attachment to peduncle (0.32) and leaf colour $(0.26)$ had the highest loadings with positive contributions to the over-all variation. The second Component axis accounted for $15.57 \%$ of the over-all variation, and included traits such as twinning tendency $(0.23)$, pod curvature $(0.59)$, leaf colour $(0.45)$ and pod colour (0.47) with highest loadings and positive contributions. The third Component axis explained $13.52 \%$ of the entire variation and included traits terminal leaflet shape (0.43), pod attachment to peduncle (0.41), immature pod pigmentation (0.32), and leaf colour $(0.22)$ and pod colour (0.33) with the highest loadings and positive contributions. The fourth Component axis explained $10.93 \%$ of the entire variation and included traits such as plant hairiness $(0.58)$, immature pod pigmentation $(0.27)$ and pod colour $(0.37)$ with the highest loadings and positive contributions. The fifth component axis accounted for $9.26 \%$ of the total variation and included traits like growth pattern $(0.29)$, terminal leaflet shape $(0.30)$, pod curvature $(0.23)$ and flower colour $(0.71)$ with the maximum loadings and positive contributions. The last axis (PC6) explained just $8.89 \%$ of the entire variation with positive contributions from traits such as raceme position (0.70), pod attachment to peduncle (0.48) and flower colour $(0.40)$.

Bi-plot of qualitative traits based on Principal Component axes 1 and 2 is presented in Figure 2. The genotype (accession) $x$ trait bi-plot resulted in four different groups for the accessions. Group I consisted of seven accessions (AC25, AC21, AC17, AC16, $A C 10, A C 01$ and AC08) on the right side of the curvex hul. Group II consisted of five accessions (AC20, AC09, AC11, AC22 and AC04). Group III consisted of eight accessions (AC19, AC06, AC07, AC13, AC14, AC12, AC05 and AC02). Group IV consisted of five accessions (AC18, AC03, AC23, AC24 and AC15). Accessions in groups I and II were positively correlated with traits such as growth pattern, plant hairiness, and pod attachment to peduncle, twinning tendency, leaf colour and pod colour. Accessions in group III were positively correlated with raceme position, flower colour and terminal leaflet shape. Accessions in group IV were more positively correlated with pod curvature, plant pigmentation and immature pod pigmentation. Positive correlations existed among traits such as growth pattern, plant hairiness and pod attachment to peduncle. These traits were also positively correlated with pod colour, leaf colour and twinning tendency, all of which were positively correlated too. Pod curvature was positively correlated with plant pigmentation. Plant pigmentation was positively correlated with immature pod pigmentation and raceme position and flower colour. 
Table-3: Mean values of qualitative traits of 25 accessions of cowpea

\begin{tabular}{|c|c|c|c|c|c|c|c|c|c|c|c|c|}
\hline ACC & GTP & TWT & PP & TLS & PHR & RP & PAP & PC & IPP & LC & FC & PODC \\
\hline $\mathrm{AC} 01$ & 1 & 5 & 1 & 1 & 3 & 3 & 7 & 0 & 1 & 7 & 1 & 3 \\
\hline $\mathrm{AC02}$ & 1 & 3 & 5 & 2 & 5 & 3 & 3 & 0 & 1 & 3 & 4 & 2 \\
\hline AC03 & 1 & 5 & 3 & 3 & 3 & 3 & 5 & 5 & 3 & 7 & 1 & 2 \\
\hline AC04 & 2 & 0 & 1 & 3 & 3 & 2 & 5 & 3 & 4 & 7 & 2 & 3 \\
\hline AC05 & 1 & 3 & 5 & 2 & 5 & 2 & 3 & 0 & 4 & 3 & 2 & 2 \\
\hline AC06 & 2 & 5 & 5 & 3 & 5 & 3 & 5 & 3 & 4 & 5 & 2 & 1 \\
\hline AC07 & 2 & 3 & 7 & 1 & 3 & 2 & 5 & 3 & 1 & 5 & 2 & 2 \\
\hline AC08 & 2 & 3 & 3 & 1 & 5 & 1 & 5 & 3 & 2 & 7 & 4 & 2 \\
\hline AC09 & 2 & 5 & 0 & 1 & 7 & 2 & 5 & 3 & 0 & 5 & 2 & 2 \\
\hline AC10 & 2 & 7 & 5 & 1 & 5 & 3 & 5 & 5 & 1 & 7 & 2 & 2 \\
\hline $\mathrm{AC} 11$ & 2 & 0 & 1 & 4 & 7 & 1 & 7 & 0 & 2 & 7 & 1 & 3 \\
\hline AC12 & 1 & 3 & 7 & 2 & 3 & 3 & 5 & 5 & 4 & 5 & 3 & 1 \\
\hline AC13 & 1 & 5 & 7 & 2 & 3 & 3 & 5 & 3 & 1 & 7 & 2 & 1 \\
\hline $\mathrm{AC} 14$ & 1 & 5 & 7 & 2 & 3 & 3 & 5 & 3 & 2 & 5 & 2 & 2 \\
\hline AC15 & 1 & 7 & 9 & 2 & 3 & 3 & 3 & 7 & 5 & 7 & 3 & 4 \\
\hline AC16 & 2 & 7 & 1 & 2 & 3 & 1 & 5 & 5 & 0 & 7 & 2 & 2 \\
\hline $\mathrm{AC} 17$ & 2 & 7 & 3 & 1 & 7 & 1 & 5 & 5 & 2 & 7 & 3 & 2 \\
\hline AC18 & 1 & 3 & 9 & 2 & 3 & 1 & 3 & 5 & 4 & 5 & 3 & 2 \\
\hline AC19 & 1 & 7 & 1 & 2 & 3 & 1 & 1 & 1 & 0 & 5 & 1 & 0 \\
\hline AC20 & 2 & 7 & 3 & 1 & 7 & 3 & 5 & 0 & 2 & 7 & 3 & 2 \\
\hline AC21 & 2 & 5 & 1 & 1 & 5 & 1 & 7 & 3 & 0 & 7 & 1 & 3 \\
\hline AC22 & 2 & 7 & 0 & 4 & 3 & 1 & 7 & 0 & 0 & 7 & 4 & 0 \\
\hline AC23 & 1 & 3 & 7 & 2 & 3 & 3 & 7 & 5 & 1 & 7 & 3 & 2 \\
\hline AC24 & 1 & 5 & 9 & 2 & 3 & 1 & 3 & 7 & 2 & 7 & 2 & 3 \\
\hline AC25 & 2 & 7 & 0 & 1 & 7 & 1 & 5 & 5 & 0 & 7 & 2 & 3 \\
\hline Mean & 1.52 & 4.68 & 4 & 1.92 & 4.28 & 2.04 & 4.84 & 3.2 & 1.84 & 6.12 & 2.28 & 2.04 \\
\hline Max & 2 & 7 & 9 & 4 & 7 & 3 & 7 & 8 & 5 & 7 & 4 & 4 \\
\hline Min & 1 & 0 & 0 & 1 & 3 & 1 & 1 & 0 & 0 & 3 & 1 & 0 \\
\hline SD & 0.50 & 2.09 & 3.05 & 0.89 & 1.59 & 0.92 & 1.49 & 2.29 & 1.55 & 1.28 & 0.92 & 0.92 \\
\hline CV (\%) & 32.89 & 44.44 & 76.25 & 46.35 & 37.15 & 45.09 & 30.58 & 71.56 & 84.24 & 20.92 & 40.35 & 45.09 \\
\hline $\begin{array}{l}\mathrm{H}^{2} \mathrm{~B} \\
(\%)\end{array}$ & $\begin{array}{l}100.0 \\
0\end{array}$ & $\begin{array}{l}100.0 \\
0\end{array}$ & 100.00 & $\begin{array}{l}100.0 \\
0\end{array}$ & 100.00 & 100.00 & $\begin{array}{l}100.0 \\
0\end{array}$ & 100.00 & $\begin{array}{l}100.0 \\
0\end{array}$ & $\begin{array}{l}100.0 \\
0\end{array}$ & $\begin{array}{l}100.0 \\
0\end{array}$ & $\begin{array}{l}100.0 \\
0\end{array}$ \\
\hline
\end{tabular}

GTP: Growth pattern; TWT: Twinning tendency; PP: Plant pigmentation; TLS: Terminal leaflet shape; PHR: Plant hairiness; RP: Raceme position; PAP: Pod attachment to peduncle; PC: Pod curvature; IPP: Immature pod pigmentation; LC: Leaf colour, FC: Flower colour; PODC: Pod colour; SD: Standard variation; CV: Coefficient of variation; H²B: Heritability.

Table-4: Genotypic correlation among 12 qualitative traits of 25 accession of cowpea

\begin{tabular}{|l|l|l|l|l|l|l|l|l|l|l|l|l|}
\hline & GTP & TWT & PP & TLS & PHR & RP & PAP & PC & IPP & LC & FC & PODC \\
\hline GTP & & 0.03 & $-0.58^{* *}$ & -0.09 & $0.57^{* *}$ & -0.39 & $0.43^{*}$ & -0.13 & -0.31 & 0.34 & 0.03 & 0.04 \\
\hline TWT & & & -0.13 & -0.34 & 0.08 & -0.01 & -0.15 & 0.21 & -0.37 & 0.26 & 0.03 & -0.20 \\
\hline PP & & & & -0.05 & $-0.43^{*}$ & 0.39 & -0.37 & $0.49^{*}$ & $0.53^{* *}$ & -0.25 & 0.27 & 0.09 \\
\hline TLS & & & & & -0.27 & -0.05 & 0.11 & -0.18 & 0.28 & 0.01 & -0.02 & -0.24 \\
\hline PHR & & & & & & -0.20 & 0.15 & -0.24 & -0.17 & 0.00 & 0.02 & 0.18 \\
\hline RP & & & & & & & 0.06 & -0.04 & 0.32 & -0.18 & 0.03 & 0.00 \\
\hline PAP & & & & & & & & -0.18 & -0.29 & $0.52^{* *}$ & -0.08 & 0.12 \\
\hline PC & & & & & & & & & 0.24 & 0.34 & 0.03 & 0.32 \\
\hline IPP & & & & & & & & & & -0.19 & 0.14 & 0.23 \\
\hline LC & & & & & & & & & & & -0.13 & 0.30 \\
\hline FC & & & & & & & & & & & & -0.20 \\
\hline PODC & & & & & & & & & & & \\
\hline
\end{tabular}

GTP: Growth pattern; TWT: Twinning tendency; PP: Plant pigmentation; TLS: Terminal leaflet shape; PHR: Plant hairiness; RP: Raceme position; PAP: Pod attachment to peduncle; PC: Pod curvature; IPP: Immature pod pigmentation; LC: Leaf colour, FC: Flower colour; PODC: Pod colour 


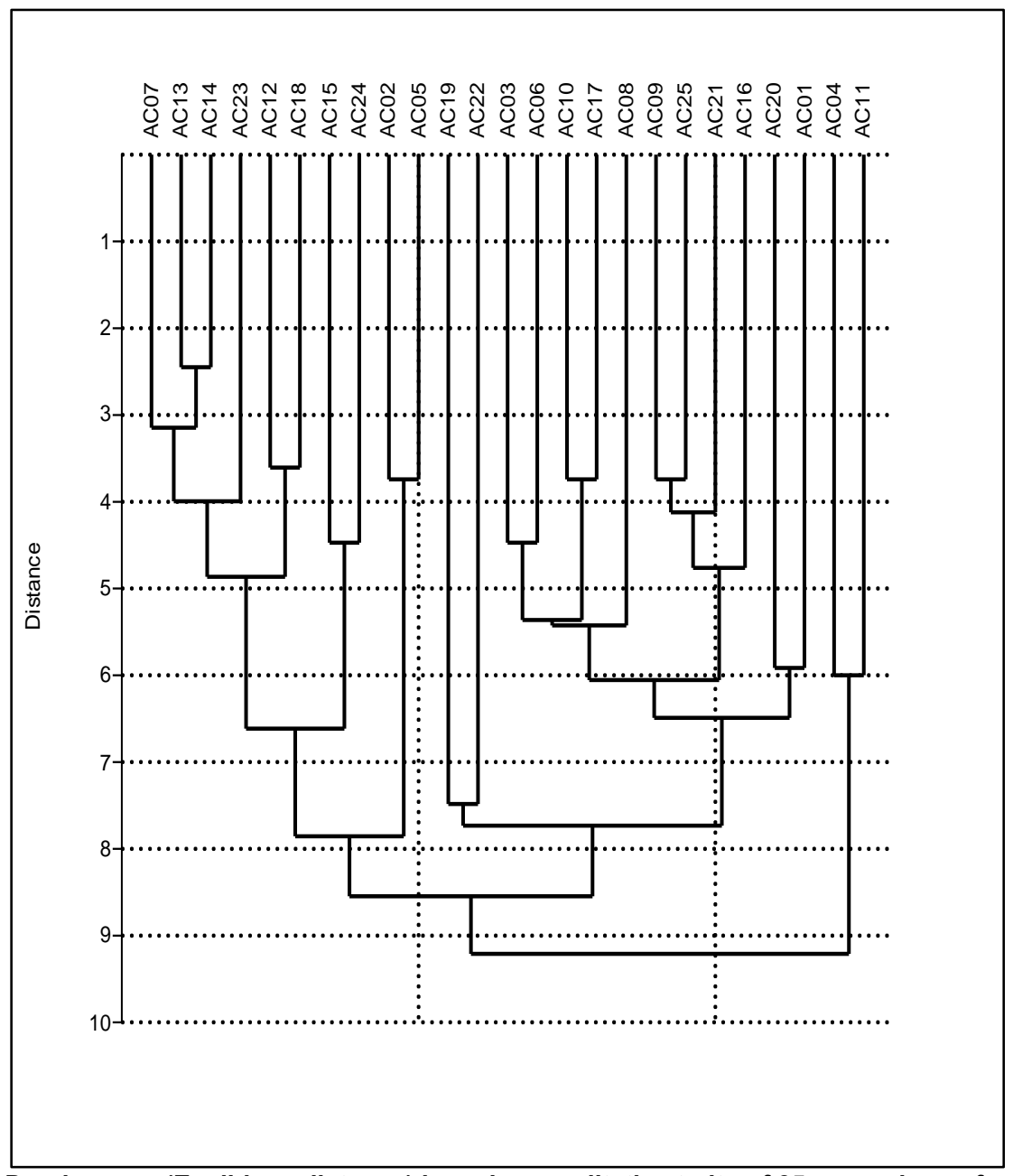

Fig-1: Dendrogram (Euclidean distance) based on qualitative traits of 25 accessions of cowpea

Table-5: Principal Component analysis based on qualitative traits of 25 accessions of cowpea for 2015 planting season

\begin{tabular}{|l|l|l|l|l|l|l|}
\hline \multicolumn{7}{|c|}{ Principal Components } \\
\hline & PC1 & PC2 & PC3 & PC4 & PC5 & PC6 \\
\hline Eigen-value & 3.12 & 1.87 & 1.62 & 1.31 & 1.11 & 1.06 \\
\hline Cumulative Eigen-value & 3.12 & 4.99 & 6.61 & 7.92 & 9.03 & 10.1 \\
\hline Variability (\%) & 26.02 & 15.57 & 13.52 & 10.93 & 9.26 & 8.89 \\
\hline Cumulative variability (\%) & 26.02 & 41.59 & 55.11 & 66.04 & 75.3 & 84.19 \\
\hline Variables & PC1 & PC2 & PC3 & PC4 & PC5 & PC6 \\
\hline Growth pattern & $\mathbf{0 . 4 5}$ & 0.04 & 0.07 & 0.19 & $\mathbf{0 . 2 9}$ & 0.05 \\
\hline Twinning tendency & 0.13 & $\mathbf{0 . 2 3}$ & $\mathbf{- 0 . 5 6}$ & $-\mathbf{0 . 2 8}$ & 0.00 & 0.12 \\
\hline Plant pigmentation & $\mathbf{- 0 . 4 8}$ & 0.19 & -0.03 & 0.06 & 0.12 & 0.13 \\
\hline Terminal leaflet shape & -0.08 & $-\mathbf{0 . 3 3}$ & $\mathbf{0 . 4 3}$ & $-\mathbf{0 . 3 3}$ & $\mathbf{0 . 3 0}$ & -0.19 \\
\hline Plant hairiness & $\mathbf{0 . 3 4}$ & -0.01 & -0.06 & $\mathbf{0 . 5 8}$ & 0.00 & 0.08 \\
\hline Raceme position & $\mathbf{- 0 . 2 7}$ & -0.01 & 0.07 & -0.02 & $-\mathbf{0 . 3 6}$ & $\mathbf{0 . 7 0}$ \\
\hline Pod attachment to peduncle & $\mathbf{0 . 3 2}$ & 0.05 & $\mathbf{0 . 4 1}$ & -0.19 & 0.00 & $\mathbf{0 . 4 8}$ \\
\hline Pod curvature & -0.18 & $\mathbf{0 . 5 9}$ & -0.05 & -0.10 & $\mathbf{0 . 2 3}$ & -0.17 \\
\hline Immature pod pigmentation & $\mathbf{- 0 . 3 8}$ & 0.05 & $\mathbf{0 . 3 2}$ & $\mathbf{0 . 2 7}$ & 0.18 & -0.03 \\
\hline Leaf colour & $\mathbf{0 . 2 6}$ & $\mathbf{0 . 4 5}$ & $\mathbf{0 . 2 2}$ & $-\mathbf{0 . 3 6}$ & 0.17 & 0.09 \\
\hline Flower colour & -0.11 & -0.07 & -0.19 & 0.19 & $\mathbf{0 . 7 1}$ & $\mathbf{0 . 4 0}$ \\
\hline Pod colour & 0.01 & $\mathbf{0 . 4 7}$ & $\mathbf{0 . 3 3}$ & $\mathbf{0 . 3 7}$ & $\mathbf{- 0 . 2 2}$ & -0.09 \\
\hline
\end{tabular}




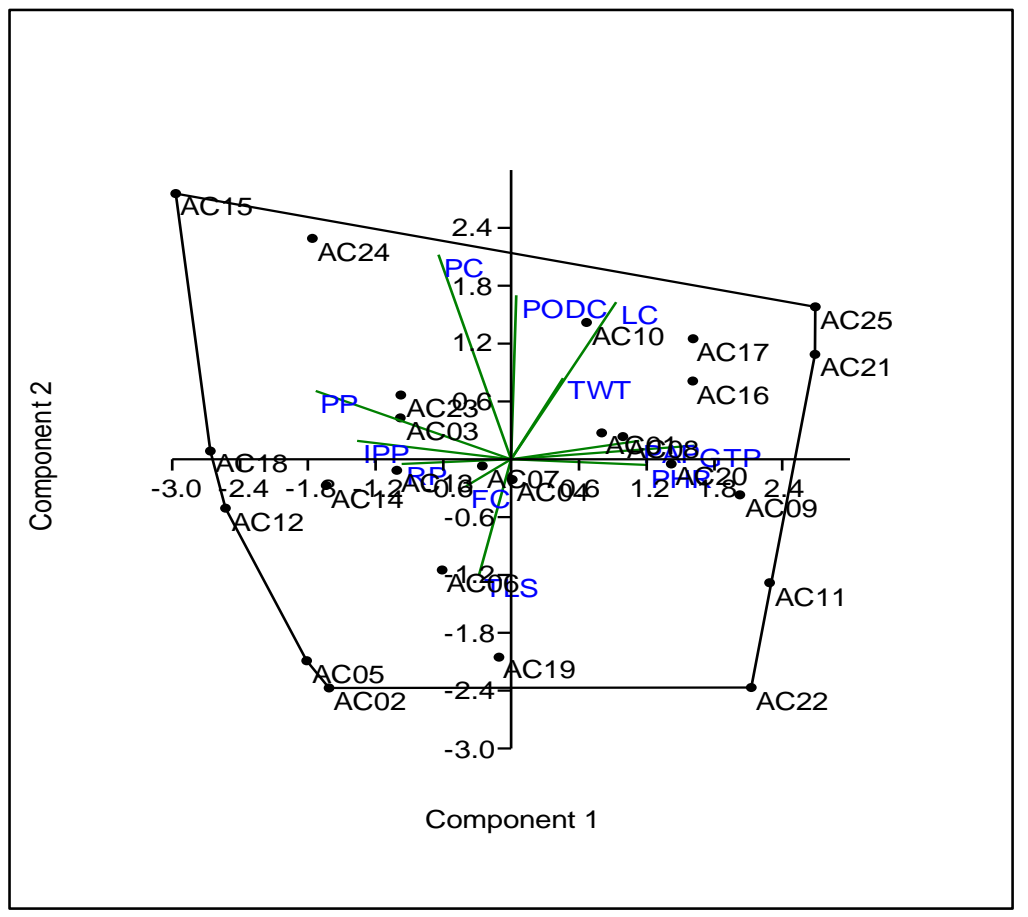

Fig-2: Bi-plot of Principal Component analysis based on qualitative traits of 25 accessions of cowpea

\section{DISCUSSION}

A better understanding of the extent and nature of the existing genetic variability for various traits, the extent of character heritability, inter character association and their effects directly and indirectly on yield among available individuals of a germplasm collection, is a prerequisite for breeding new ones with improved characters. The level of variations showed by qualitative traits was very high, as all the 12 traits studied were able to differentiate efficiently among the accessions. Heritability estimate for all traits was 100 percent, which demonstrated that environmental condition had insignificant impact on qualitative traits in cowpea. This is in line with the findings of Ngompe-Deffo et al. [11]. The most variable trait was immature pigmentation, while the trait with the least variation was leaf colour.

The observed growth pattern among accessions revealed that the growth pattern of 48 percent of accessions were determinate, while 52 percent were of indeterminate growth pattern. Eight percent $(8 \%)$ of the accessions did not twine, 28 percent were slightly twinned, and 32 percent were moderately twinned, while 32 percent had pronounced twine stems. Twelve 12 percent of the accessions were not pigmented, 24 percent were slightly pigmented, 16 percent were moderately pigmented, 16 percent were intermediately pigmented, and 20 percent were extensively pigmented, while 12 percent were solidly pigmented. For terminal leaflet shape, 36 percent of the accessions had globose leaflet shape, those with sub-globose were 44 percent, while 12 percent had subhastate leaflet shape and only 8 percent had hastate leaflet shape. These forms of variability support the findings of Doumbia [14]. Glabrescent hairs were found in 56 percent of the accessions, hairs were short in 24 percent, whereas 20 percent had pubescent hairs.

It was revealed that 44 percent of the accessions had their racemes throughout canopy, 40 percent had their racemes mostly above canopy, while those which had their racemes in upper canopy were 16 percent. This agrees with the findings of Nkouannessi [8]. Pod attachment to peduncle showed 20 percent of the accessions to have pendant pod attachment to peduncle, 56 percent had pod attachment of $30-90^{\circ}$ to peduncle, while 20 percent had erect pod attachment to peduncle. Pod curvature revealed 25 percent of the accessions to be straight pod types, 32 percent had slightly curved pods, and 32 percent had curved pods, while 8 percent had coiled pods. Immature pod pigmentation showed that 25 percent of the accessions lacked pigmented pods, 24 percent had pigmented tips, 24 percent had pigmented sutures, and 4 percent had pigmented valves, while 20 percent had splashes of pigment. Immature pod pigmentation of all forms were not represented and variability for this trait was the highest (84.24\%). These results are similar to the findings of Nkouannessi [8] and Cobbinah et al. [15].

Eight (8) percent of the accessions had pale green leaves, 28 percent were of intermediate green leave types, whereas 64 percent had dark green leaves. Flower colour was highly variable (40.35\%) among the accessions; 20 percent of them exhibed white flowers, 44 percent of the accessions had violet flowers, 24 percent of the accession had mauve-pink flowers and 12 percent belonged to other colours. All flower colours were represented according to cowpea descriptors of IBPGR [12]. This supports the findings of Cobbinah et al. [15] and Doumbia [14]. Ajayi and Adesoye [1] also reported only violet flowers for the ten genotypes of cowpea studied. High variability level (45.09\%) was revealed in pod colour among the accessions. Dark tan mature pods were found 
among 52 percent, 12 percent had pale tan colour of pods, 24 percent had dark brown colour of pods, and then 8 percent had black pods. Pod colour of all types were represented among the accessions.

\section{Inter-character character association among qualitative traits}

Majority of the accessions (83.33\%) with determinate growth pattern were intermediate to highly pigmented, while the majority (92.31\%) of the indeterminate growth patterned accessions were either non pigmented or moderately pigmented. This resulted to the negative genotypic correlations between growth pattern and plant pigmentation. Contrary to the findings of Msengi [9], growth pattern did not have any significant correlation with immature pod pigmentation among the accessions of cowpea evaluated. Eighty three percent (83\%) of the accessions with determinate growth pattern had glabrescent hairs, while 16.67 percent of the same accessions had short hairs and none had pubescent hairs. About 30.77 percent of the accessions with indeterminate growth pattern had glabrescent hairs and short hairs, while 38.46 percent of them had pubescent hairs. Growth pattern was highly significant and positively correlated with plant hairiness. This correlation indicated that as growth pattern increased in diversity, plant hairiness also increased.

About $41.67 \%$ of accessions with determinate growth pattern had pendant attachment of pods to peduncle, 33.33 percent of them also had their pods attachment in 30 to $90^{\circ}$ down from erect, while 16.67 percent of them had erect pod attachment to peduncle. Accessions with indeterminate growth pattern had 76.92 percent of its plants with pod attachment of the 30 to $90^{\circ}$ down from erect form, while 23.08 percent of them had erect attachment of pods to peduncle. Positive correlation among growth pattern and pod attachment to peduncle suggested that more diverse growth pattern will positively affect pod attachment to peduncle.

About $66.67 \%$ of accessions without plant pigmentation had pubescent hairs, while $33.33 \%$ had glabrescent hairs. More than sixty percent $(66.67 \%)$ of accessions with very slight plant pigmentation had glabrescent hairs, while $16.67 \%$ had short and pubescent hairs. Twenty five percent $(25 \%)$ of the moderately pigmented accessions had glabrescent and short hairs, while $50 \%$ of them had pubescent hairs. All extensively pigmented accessions and all solidly pigmented accessions had glabrescent hairs. Plant pigmentation was significant and negatively correlated with plant hairiness. This suggested that accessions with higher plant pigmentation had lower plant hairiness. Selection for plants with higher pigmentation will result in plants with low hairs. About $33.33 \%$ of non-pigmented accessions had straight pods, slightly curved pods and curved pods. One third (33.33\%) of slightly pigmented accessions had straight pods and slightly curved pods, while $16.67 \%$ of them had curved pods. Twenty five (25) percent of the moderately pigmented accessions had straight pods, $25 \%$ of them also had slightly curved pods, while $50 \%$ had curved pods. Fifty (50) percent of intermediately pigmented accessions had straight pods, $25 \%$ of them had slightly curved pods and curved pods. Sixty (60) percent of accessions with extensive pigmentation had slightly curved pods, while the remaining $40 \%$ had curved pods. One third (33.33 percent) of accessions which were solidly pigmented had curved pods, while 66.67 percent of them had coiled pods. Plant pigmentation was positively correlated with pod curvature. This suggested that accessions with lower level of pigmentation had less curved pods while the ones with higher levels of pigmentation had more curved pods.

All accessions without plant pigment did not have pigmented immature pods. Fifty (50) percent of slightly pigmented accessions had no pigmented immature pods too. One in six (16.67 percent) of them had pigmented pod tips, 16.67 percent also had pods with pigmented sutures, and 16.67 percent with splashes of pigment on pods. Seventy five (75) percent of the moderately pigmented accessions had pods with pigmented tips, while $25 \%$ of them had pods with pigmented valves. Fifty (50) percent of the accessions with intermediate plant pigmentation had pods with pigmented tips, while the remaining $50 \%$ had pods with splashes of pigment. Sixty (60) percent of accessions with extensive plant pigmentation had pods with pigmented tips, $20 \%$ of them had pods with pigmented sutures, while the remaining $20 \%$ had pods with splashes of pigment. One third (33.33 percent) of accessions with solid plant pigmentation had pods with pigmented sutures; another 33.33 percent of them had pods with splashes of pigment, while the remaining 33.33 percent had pods that were uniformly pigmented. Plant pigmentation was highly significant and positively correlated with immature pod pigmentation.

About $40 \%$ of accessions with pods which had pendant attachment to peduncle had pale leaf colour, $20 \%$ of these accessions had intermediate green leaf colour, while the remaining $40 \%$ had dark green leaves. About 35.71 percent of accessions with 30 to $90^{\circ}$ down from erect form of pod attachment had intermediate green colour of leaves. About 64.28 percent of the same accessions had dark green leaves. All accessions with erect attachment of pods to peduncle had dark green leaves. Pod attachment to peduncle was highly significant and positively correlated with leaf colour. This suggested that accessions with mostly erect attachment of pods had deep green leaves while accessions with mostly pendant attachment had pale green leaves. Both positive and negative correlations among qualitative traits have been documented in cowpea and pigeonpea [9]. The use of all important correlated traits in crop improvement programmes cannot be over emphasised.

\section{Cluster analyses for qualitative traits}

Simultaneous consideration of numerous traits for many accessions required the use of cluster analysis for adequate trait representation. Cluster analysis provides a clear and more instructive display of the relative positions of accessions. Cluster analysis shrinks the number of individual variable units by categorising such variation into groups which are converted into a dendrogram using 
the coefficient of similarity; it shows arrays of interactions between genotypes and rank equally exclusive grouping in which similar descriptions are mathematically combined into same cluster $[16,17,14,1,18,11]$.

All accessions were distinct from one another at 0.00 genetic distances. Accessions were grouped in the same clusters based on similar attributes. Accessions from the United States of America and Nigeria were combined in the same cluster, while some accessions from Nigeria and Niger were also together in the same cluster. A high level of similarity was observed among two accessions (AC21 and AC25) from Nigeria; three accessions (AC06, AC03 and AC10) from USA; two accessions (AC13 and AC14) of cluster IV from Niger; and three accessions (AC12, AC23 and AC24) from Nigeria for most of the traits studied. This close similarity indicated that these accessions may have originated from the same genetic background; it could also have resulted from the fact that cowpea is a self-pollinated crop [19]. Variability in seed proteins of cowpea has been used to generate a high level of relationship among them $[20,10]$. Also classified cowpea based on qualitative traits.

\section{Principal Components Analyses (PCA) for qualitative traits}

Principal Component (PC) Analysis is an example of multivariate methods, and very effective at examining the relative contribution of individual trait [21] under a prevailing condition for diversity study in crop species. The method identifies a small set of variables that account for a large proportion of the total variance in the original variable. Information obtained from PCA may assist a plant breeder to pinpoint limited traits for use in hybridization and selection programmes [14].

The PCA of the qualitative traits showed traits such as growth pattern, raceme position, plant pigmentation, plant hairiness, pod attachment to peduncle, leaf colour, immature pod pigmentation, twinning tendency, terminal leaflet shape and pod colour as the most important traits making high contributions to the total variability. The outcome of this study supports the findings of Doumbia [14]. Many workers have used this technique in classifying and discriminating variation forms in population of crop genotypes such as ground nut [22], Tomato [23], wheat [24], rice [25, 26].

\section{$\mathrm{Bi}$ - Plots of PCA for qualitative traits}

$\mathrm{Bi}$ - plots of PCAs 1 and 2 for qualitative traits resulted in five groups. Accessions in group I and II were similar with traits like growth pattern, plant hairiness and pod attachment to peduncle, twinning tendency, leaf colour and pod colour. Group III accessions were correlated with traits like raceme position, flower colour and terminal leaflet shape. Group IV had accessions which were correlated with plant pigmentation, immature pod pigmentation, and pod curvature. The results of this study support the findings of Doumbia [14]. The first, second and fourth group accessions will be excellent genetic enhancement candidates. For instance, AC10 with indeterminate growth pattern, short hairs, 30-900 down to erect pod attachment to peduncle and dark green leaf colour and AC18 with determinate growth pattern, glabrescent hairs, pendant pod attachment to peduncle and intermediate green leaf colour would be outstanding for the programme of cowpea improvement.

\section{CONCLUSION}

Every qualitative trait was able to differentiate accessions from one another; however, some had separating limit than others. It would be very imperative to pinpoint ahead of time the privileged traits (those with high discriminative limit) before the task of genetic diversity studies. Accessions in group I, II which differed to accessions in group IV in important traits such as growth pattern, plant hairiness, pod attachment to peduncle and leaf colour are recommended together with these important traits in cowpea improvement programmes. The results of genotypic correlations were in perfect agreement with the outcomes of the bi-plot. It was discovered that the combination of PCA, bi-plot, cluster analysis and genotypic correlations were efficient in revealing significant relationships among characteristics of cowpea accessions for selection purposes, hence are therefore recommended.

\section{ACKNOWLEDGEMENT}

I hereby express my appreciation to Adekunle Ajasin University, Akungba - Akoko for approving my candidature for Post Graduate Grant which contributed in no small way to the success of this work. My sincere gratitude also goes to the Genetic Resources Centre, International Institute of Tropical Agriculture (IITA), Ibadan for supplying the accessions of cowpea used for this research. Also acknowledged are Profs. A.E. Gbadamosi and V.O. Olumekun of the Department of Plant Science and Biotechnology, Adekunle Ajasin University for their roles in the success of this research.

\section{References}

1. Ajayi, A. T., \& Adesoye, A. I. (2013). Cluster analysis technique for assessing variability in cowpea (Vigna unguiculata L. Walp) accessions from Nigeria. Ratarstvo i povrtarstvo, 50(2), 1-7.

2. Ajayi, A. T., Adekola, M. O., Taiwo, B. H., \& Azuh, V. O. (2014). Character expression and differences in yield potential of ten genotypes of cowpea (Vigna unguiculata L. Walp). International Journal of Plant Research, 4(3), 63-71.

3. Langyintuo, A. S., Ntoukam, G., Murdock, L., Lowenberg-DeBoer, J., \& Miller, D. J. (2004). Consumer preferences for cowpea in Cameroon and Ghana. Agricultural Economics, 30(3), 203-213. 
4. Kuykendall, L.D., Hashem, F.M., Dadson, R.B. and Elkan, G.K. (2000). Nitrogen Fixation. In: Lederberg, J., (Ed.) and Encyclopedia of Microbiology, Academic Press, New York, 3: 329 - 404.

5. Martins, L.M.V., Xavier, G.R., Rangel, F.W., Ribeiro, J.R.A., Neves, M.C.P., Morgado, L.B. and Rumjanek, N.G. (2003). Contribution of biological fixation to cowpea: A strategy for improving seed yield in the semi-arid regions of Brazil. Biology and Fertility of Soils, 38: $333-339$.

6. Dadson, R.B., Hashem, F.M., Javaid, I., Joshi, J., Allen, A.L and Devine, T.E. (2005). Effect of water sress on the yield of cowpea (Vigna unguiculata L. Walp.) genotypes in the Delmarva Region of the United States. Journal of Agronomy and Crops Science, 191: $210-217$.

7. Fatokun, C. A. (2002). Challenges and opportunities for enhancing sustainable cowpea production. IITA.

8. Nkouannessi, M. (2005). The genetic, morphological and physiological evaluation of African cowpea genotypes.

9. Msengi, Z. M. (2016). Genetic diversity of Tanzanian and Kenyan adapted landraces of cowpea, sorghum and pigeonpea (Doctoral dissertation, Sokoine University of Agriculture).

10. Selvi, R., Muthiah, A. R., Maheswaran, M., \& Shanmugasundaram, P. (2003). Genetic diversity analysis in the genus vigna based on morphological traits and isozyme markers. SABRAO Journal of Breeding and Genetics, 35, 103-112.

11. Ngompe-Deffo, T., Kouam, E. B., Beyegue-Djonko, H., \& Anoumaa, M. (2017). Evaluation of the Genetic Variation of Cowpea Landraces (Vigna unguiculata) from Western Cameroon Using Qualitative Traits. Notulae Scientia Biologicae, 9(4), 508-514.

12. IBPGR. (1983). International board for plant genetic resources cowpea descriptors, Rome, Italy, 30

13. Hammer, Ø., Harper, D. A., \& Ryan, P. D. (2001). PAST: paleontological statistics software package for education and data analysis. Palaeontologia electronica, 4(1), 9.

14. Ibrahima, Z. D. (2012). Comparative study of cowpea germplasm from Ghana and Mali using morphological and molecular markers (Doctoral dissertation).

15. Cobbinah, F. A., Addo-Quaye, A. A., \& Asante, I. K. (2011). Characterization, evaluation and selection of cowpea (Vigna unguiculata (L.) walp) accessions with desirable traits from eight regions of Ghana. Journal of Agricultural and Biological Science, 6(7), 21-32.

16. Hair, J., Anderson, R., Tatham, R. and Black, W. (1995). Multiple discriminant analysis. Multivariate Data Analysis with Readings. Englewood Cliffs: Prentice-Hall International Inc. $178-237$.

17. Aremu, C. O., Ariyo, O. J., \& Adewale, B. D. (2007). Assessment of selection techniques in genotype $X$ environment interaction in cowpea Vigna unguiculata (L.) walp. African Journal of Agricultural Research, 2(8), 352-355.

18. Ajayi, A.T., Osekita, O.S. and Adekola, M.O. (2014b). Expression of traits in cowpea (Vigna unguiculata L. Walp) as revealed by cluster analysis. International Agriculture Congress, Pullman Putrajaya Lakeside, Putrajaya, Malaysia, 25 - 27 November, 2014. Pp. $135-143$.

19. Padulosi, S. (1993). Genetic diversity, taxonomy and ecogeographic survey of the wild relatives of Cowpea, Vigna unguiculata (L.) Walp. Ph.D. Thesis, University Catholique de Louvain-La Neuve, Belgium. Pp. 477.

20. Paino, D. U., Pedalino, M., Grillo, S., Rao, R., \& Tucci, M. (1990). Variability in major seed proteins in different Vigna species. Cowpea genetic resources., 90-100.

21. Vijayan, S. (2005). Statistical analysis of influence of morphological characters on yield in selected vegetable crops(Doctoral dissertation, UAS, Dharwad).

22. Makinde, S. C. O., \& Ariyo, O. J. (2010). Multivariate analysis of genetic divergence in twenty two genotypes of groundnut (Arachis hypogaea L.). Journal of Plant Breeding and Crop Science, 2(7), 192-204.

23. Evgenidis, G., Traka-Mavrona, E., \& Koutsika-Sotiriou, M. (2011). Principal component and cluster analysis as a tool in the assessment of tomato hybrids and cultivars. International Journal of Agronomy, 2011.

24. Khodadadi, M., Fotokian, M. H., \& Miransari, M. (2011). Genetic diversity of wheat (Triticum aestivum L.) genotypes based on cluster and principal component analyses for breeding strategies. Australian Journal of Crop Science, 5(1), 17.

25. Gana, A. S., Shaba, S. Z., \& Tsado, E. K. (2013). Principal component analysis of morphological traits in thirty-nine accessions of rice (Oryza sativa L.) grown in a rainfed lowland ecology of Nigeria. Journal of Plant Breeding and Crop Science, 4(6), $120-126$.

26. Osekita, O.S. (2018). Genotype x environment interaction and molecular diversity studies of selected rice genotypes across three Nigerian agro - ecological zones. Ph.D. Thesis, Department of Crop, Soil and Pest Management, Federal University of Technology, Akure, Nigeria,199. 